\title{
Macroscopic Structure of the Fin-Rays and Their Annuli in Pectoral and Pelvic Fins of Chinook Salmon, Oncorhynchus tshawytscha
}

\author{
LEONOR C. G. FERREIRA, ${ }^{1}$ RICHARD J . BEAMISH, ${ }^{2}$ \\ AND J OHN H. YOUSON ${ }^{1 *}$ \\ 1Department of Zoology and Division of LifeSciences, University of Toronto \\ at Scarborough, Scarborough, Ontario M 1C 1A4 Canada \\ ${ }^{2}$ Department of Fisheries and Oceans, Fisheries Research Branch, Pacific \\ Biological Station, Nanaimo, British Columbia V9R 5K6 Canada
}

\begin{abstract}
Light microscopy, enzyme clearing, and staining techniques were used to describe the structure of fin-rays in pectoral and dorsal fins of adult and juvenile chinook salmon,Oncorhynchus tshawytscha. In addition, several decal cification agents, fixatives, and staining methods were employed to demonstrate and determine the nature of the fin-ray annulus (yearly growth ring). Etched, transverse sections of fin-rays were examined by scanning electron microscopy (SEM). A description is provided of specific morphological regions along the length of fin-rays in both fins. Each ray consists of parallel halves, medial and lateral hemisegments, which diverge proximally and embrace underlying radial cartilages and are segmented distally. Fibrocartilage masses are associated with bone and hyaline cartilage in the proximal regions. There is evidence of periosteal, and perhaps endochondral, osteogenesis in the fin-rays. A novel fixation-staining method is described to depict the fin ray annulus in adult chinook salmon. Transverse sections of rays of adults, but not juveniles, demonstrate alternating narrow-dark and wide-light purple bands following prol onged decalcification/fixation in Bouin's fluid only with subsequent hematoxylin-eosin staining. The dark and light bands correspond to translucent (annuli) and opaque zones, respectively, in dried, unstained sections in transmitted light and in backscatter SEM. In conjunction with different light microscopic staining procedures, etched, transverse sections of fin-ray bone in SEM suggest that annuli are a manifestation of an ordered regionalization of the extracellular matrix of the bone in the fin-rays. J . M orphol. 239:297-320, 1999. @ 1999 Wiley-Liss, Inc.

KEY WORDS: fin-ray; Oncorhynchus tshawytscha; annuli
\end{abstract}

The ability to age fish is important in fisheries management and calcified structures (i.e., osseochronometry), such as scales, otoliths, opercular bones, vertebrae, dorsal spines, and fin-rays, are useful tools. In all these osseous structures, age determination is dependent upon recognizable yearly growth rings, referred to as annuli. Many definitions exist to describe exactly what the annulus and its accompanying structures represent, but most recently Cassel man ('87) clearly explained that age determination should be expressed as a systematic, yet subjective interpretation of various "checks," "breaks" or "changes in spacing," or "zones" that, based on their translucency, are optically different. Checks or zones, considered to be associated with yearly deposited annular rings, referred to as "annuli," are then enumerated to determine age.

Like mammals, tel eosts possess both compact and spongy bone formed from either

Contract grant sponsor: Department of Fisheries and Oceans, Canada; Contract grant sponsor: Natural Science and Engineering Research Council of Canada (NSERC).

*Correspondence to: J.H. Youson, Department of Zoology and Division of Life Sciences, University of Toronto at Scarborough, Scarborough, Ontario M 1C 1A4 Canada. E-mail: youson@scar.utoronto.ca 
lamellar or woven forms and there is histological evidence of osseous resorption and redeposition found in both types (M oss, '61a). Although teleost bone lacks true osteons, it does nonetheless have numerous vascular channels. These channels, referred to as primary osteons, commonly anastomose with each other through lateral branching canals that appear to be homologous to the Volkmann's canals of mammals (Moss,'61a). The organic components and the inorganic/organic ratio of piscine bone is similar to that described for other vertebrates (Moss and Posner, '60).

In contrast to the situation in higher vertebrates, however, teleost bone is unique in that it may be totally devoid of osteocytes (Parenti, '86). Based on the presence or absence of enclosed osteocytes, piscine bone is identified as osteocytic (cellular) or anosteocytic (acellular), respectively (Weiss, '78). In some extreme instances the endoskel etal elements of fish may contain a mixture of cellular and acellular types (M oss, '61a). Piscine osteogenesis is described as either periosteal or chondroidal (M oss, '61b, '63). Chondroidal osteogenesis is a process unique to teleosts and enables the direct transformation of chondroid (a nonvascular, cellular tissue). Periosteal osteogenesis is the formation of bone through metaplasia of fibroblasts and their differentiation into osteoblasts within the periosteum.

Descriptions of the histological structure of the mineralized tissues used in ageing of tel eosts have mainly focused on otoliths. Although it has been demonstrated that annuli are an integral part of the internal calcified components of the fish skel eton, our current knowledge of ageing does not include a detailed study of annulus composition and structure. Given the importance of ageing to fisheries management and the present concern of declining commercial fish stocks, there is a need to correct this deficiency in our knowl edge of ageing.

The overall goal of our study is to elucidate the internal constituents of the fin-ray annulus in chinook salmon. However, to date there has not been a study of this type carried out on fin-rays for any fish species. It is not the focus of this study to determine age by the enumeration of annuli, but instead to elucidate the actual structure and composition of these yearly deposited increments using light microscopy, scanning el ectron microscopy, and transmission electron micros- copy. The availability and the ease with which fin-rays are removed and their usefulness in determining age of long-lived species makes these structures an ideal choice of study. The present report is the first of a two part series. In this first part, the objectives are:(1) to document in detail the macroscopic structure and arrangement of fin-rays in both the pectoral and dorsal fins by the use of light microscopy and enzyme-cl earing and staining techniques; (2) to describe and compare the presence of the annulus in juvenile and adult salmon using light microscopy; and (3) to use scanning electron microscopic techniques in order to describe the three-dimensional appearance and relative amounts of inorganic salts present within the differing regions of the fin-ray.

MATERIALS AND METHODS Animal and tissue collection

Chinook salmon, Oncorhynchus tshawytscha, were collected by fishermen trollfishing in various areas throughout theStrait of Georgia, British Columbia, during the months of September to May and in February. Upon capture of the animals, their length, weight, and sex were recorded. All fish were killed by a sharp blow to the head and the immediate removal of both the left and right pectoral fins and the dorsal fin followed. Randomly, fins were either placed in small envelopes and air dried, or in solutions of either Bouin's fixative, $10 \%$ buffered formalin, or $2.5 \%$ glutaraldehyde in a phosphate buffer, pH 7.4 (Warshawsky and Moore, '67) for further processing at a later time. In conjunction with the above procedures, scales were also taken from designated areas on the same fish, as outlined in an earlier report by the International North Pacific Fisheries Commission ('59). All fins to be analyzed for light and electron microscopy were shipped to the laboratory at the University of Toronto at Scarborough, from the Pacific Biological Station in Nanaimo, B.C. Dried fins and scales remained at the Station for analysis.

In order to compare fin-ray annuli of older and younger individuals, the Ministry of Natural Resources of Ontario at Ringwood, Ontario, provided juvenile chinook salmon (approximately 130-150 days old).

\section{Enzyme clearing and staining}

This technique was modified from that of Dingerkus and Uhler ('77). Formalin-fixed 
samples were rinsed in two changes of distilled water for 5 min each followed by complete immersion of the fin in an alcian blue staining solution for 24-48 hr or until the tissue was light blue in color. This stain was specific for the identification of cartilage. Fins were then hydrated in a graded series of ethanols for $30 \mathrm{~min}$ each and subsequently bleached in a 1:9 part solution of $3 \%$ hydrogen peroxide to $1 \%$ potassium hydroxide under di rect light to enhance and accel erate the bleaching procedure. Clearing and digestion of adhering tissues were accomplished in a trypsin-buffer (3\% solution of trypsin) solution ten times the volume of the specimen, and subsequently stained with a $1 \%$ solution of alizarin red in sodium borate. This latter stain is specific for bone. Extraneous dye was removed in one to two changes of $1 \%$ potassium hydroxide and glycerine. Fins were stored in a $100 \%$ glycerine solution with thymol crystals added.

\section{Light microscopy}

A total of 20 fins, representing samples from 11 fish $(35-70 \mathrm{~cm})$ were processed for routine light microscopy. With most of the samples used, both fixation and decalcification of entire fins were achieved by storing individual samples in Bouin's fixative (Humason, '67) for 6 months to 1 year. In some cases, however, fins were fixed in $10 \%$ buffered formalin and were decalcified in solutions of $1 \mathrm{~N}$ nitric acid, $4 \mathrm{~N}$ formic acid, or $0.2 \mathrm{M}$ ethylene diamine tetraacetic acid (EDTA, Sigma Chemical Co., St. Louis, MO). Decalcification of fins varied between hours to days and was dependent upon the solution and thesize of the sample used. A simple experiment was carried out to determine which decalcifying solution best demineralized the fin-ray bone in the shortest time possible. Complete decalcification of bone was indicated using an ammonium oxalate solution (Clayden, '52). A few drops of the decalcifying solution were placed into the ammonium oxalate. If a precipitate formed, the decal cifying sol uti on was replaced. If the ammonium oxalate solution remained clear, however, this indicated decalcification was complete. All tissues were then transferred into $70 \%$ ethanol for storage. In those samples exposed to Bouin's for prolonged periods of time, however, lithium carbonate (Fisher Scientific, Fairlawn, NJ ) was added to the ethanol to remove excess picric acid.

Following fixation, tissues were dehydrated in a graded series of ethanols, cleared in Histoclear (National Diagnostics, Manville, NJ , or Diamed Lab Supplies I nc., Mississauga, Ont.) and infiltrated and embedded in Tissue Prep paraffin (m.p. $56.6^{\circ} \mathrm{C}$, Fisher Scientific). Blocks of tissue were serially sectioned in transverse and horizontal planes, 5-8 $\mu \mathrm{m}$ in thickness. All sections were mounted on pre-cleaned slides (Baserga and Malamud, '69) with dilute egg albumen. Dried slides were then deparaffinized in $\mathrm{His}$ toclear, rehydrated and stained with Ehrlich's hematoxylin, and counterstained with eosin (Sheehan and Hrapchak, '80), dehydrated in ethanol, cleared in Histoclear, and mounted with Permount (Fisher Scientific). In order to determine the tissue constituents of the fin-ray annulus, a number of other staining procedures were also employed such as Feulgen's, Masson's trichrome, periodic acid-Schiff, and Mallory Heidenhain (Sheehan and H rapchak, '80).

\section{Scanning el ectron microscopy}

Pectoral fins of trout, Oncorhynchus mykiss, were used for prelimi nary studies to establish proper techniques for scanning electron microscopy. At that time, individual rays were dissected and as much adherent soft tissue as possible was removed. Each cross-sectional area was then filed and etched. Filing was achieved by the use of sandpaper that varied in degrees of grit thickness. Etching was accomplished by the use of a 5-10\% solution of EDTA followed by a 5-10\% solution of sodium hypochlorite (NaOCl, Mallinckrodt, Paris, KY), an organic dissolving agent. Rays remained in these solutions at varying times between 1-20 $\mathrm{min}$. Following the etching procedure, rays were dehydrated in a graded series of ethanols and allowed to air dry for 24-48 hr. In some cases samples were dehydrated and exposed to a drying agent, hexamethyldisilazane (HMDS) according to Nation ('83) and then allowed to air dry for $15 \mathrm{~min}$ to $1 \mathrm{hr}$. Small samples were dehydrated in a graded series of acetones and critical point dried in carbon dioxide.

A modification of the above procedure was used on fins of chinook salmon, in order to maintain the integrity of the bone matrix and the surrounding connective tissues. Three to five fin-rays were left intact and cut away from the remaining fin al ong the length of the ray. Each sample was then dehydrated in a graded series of ethanols, postfixed in $2 \%$ osmium tetroxide in a phosphate buffer ( $\mathrm{pH}$ 7.4) for $1 \mathrm{hr}$, and completely infil- 
trated and embedded in a modified Epon/ Araldite resin (Luft, '61). To embed fin-rays for further processing, disposable 10-cc syringes were used (Becton-Dickinson, Rutherford, $\mathrm{NJ}$ ). These were filled with resin and the fin-ray placed parallel to the length of the syringe.

Once polymerization of the plastic was complete, fin-rays were cut in cross section using a Buehler I somet diamond saw (TecMet Inc., Toronto, Ont) to approxi mately 1.9 $\mathrm{mm}$ in thickness. Cutting and subsequent preparation were carried out at the Department of Geol ogy, University of Toronto. Surface preparation was accomplished initially using 9- $4 \mathrm{~m}$ diamond spray on Pan-W paper for $1 \mathrm{hr}$ at approximately 30 revolutions per min (R.P.M.) on a Buehler 8-inch, reciprocal, variable-speed polisher. Subsequently, 1 and $0.025 \mu \mathrm{m}$ diamond paste were placed on Pan-W paper for $1 \mathrm{hr}$ and $30 \mathrm{~min}$, respectively, at 15 R.P.M. Following each polishing procedure, surfaces were cleaned with $95 \%$ ethanol. Etching of fin-ray cross-sectional surfaces was then accomplished by the immersion of fin-ray tissues in various solutions such as EDTA, Baxter decalcifying solution (Baxter, McGraw Park, IL), or Decal (National Diagnostics, Manville, NJ ).

Fin-rays to be examined using the Hitachi S-530 scanning electron microscope were mounted on aluminum specimen mounts and were gold coated using a Polaron PS3 Sputter Coater. To examine differences in densities within the fin-rays, some samples were examined using a J OEL (Peabody, MA) 820 scanning el ectron microscope at The Hospital for Sick Children, Toronto. In this case, secondary el ectrons were used and samples were coated with carbon using the Denton bench top Turbo Carbon Coater.

\section{Preparation of dried fin-ray and scalesamples}

The following procedures were carried out by the technicians in a special Fish Ageing Laboratory located at the Pacific Biological Station, Department of Fisheries and Oceans in Nanaimo, B.C. The techniques explained below can be found in manuals written by MacLellan ('87) and York ('87) and in an article by Chilton and Beamish ('82).

Fins were removed using bone cutters, ensuring that the fin-ray bases were included. Prior to air drying, fins were placed in $14.5 \mathrm{~kg} \mathrm{Kraft}$ ungummed envel opes making certain the cut edge of each fin was placed at the open end of the envelope while the cut surface remained perpendicular to the long axis of the rays.

Depending upon ambient temperatureand humidity, fins were left to dry for up to 3 weeks. Fins were then trimmed and excess rays and adhering tissues removed. E poxy (Dexter Corporation, Vancouver, B.C.) was then applied smoothly up to approximately $3.5 \mathrm{~cm}$ from the basal area of the fin to provide rigid support for sectioning. Epoxied fins were al lowed to dry for 3-4 days, after which timethey weresectioned using a B ronmill sectioning machine to approximately 1.3-1.5 mm in thickness. Sections were then placed on glass slides and covered with Flotexx liquid mounting medium (Lerner Laboratories, Pittsburgh, PA.) Dried fin-ray samples were analyzed using either re flected or transmitted light in compound or stereo-mi croscopes.

As mentioned previously, all scales were removed from fish according to a designated area outlined by the International North Pacific F isheries Commission ('59). This designated area is usually above the lateral line on a diagonal from the posterior insertion of the dorsal fin toward the origin (anterior insertion) of the anal fin. Upon removal, scales were checked for deformation and re generation. If theselatter features were present, the scale was discarded and another scale removed. Scal es, with their rough sides facing upwards, were then placed in specific scale booklets possessing pages with an adhesive coating. All information was then recorded in this booklet. Scales were then examined using an Eberbach microprojector with a 40X magnification or on a microfiche reader-printer.

Interpretation of fish age estimates was based upon the identification of an annulus. In dried fin-ray sections this interpretation is based upon the presence of translucent or hyaline zones and in scales by areas of crowded circuli. All ages were determined from the scales by highly trained individuals at the ageing laboratory in Nanaimo. Along with the data on scale ages, slides of dried, fin-ray samples were also sent to the laboratory at the University of Toronto at Scarborough and photographed according to the methods described above for light microscopy.

\section{RESULTS \\ Terminology}

Figure 1 defines the terms presented in this section and how they refer to the position and location of fin-rays within the pecto- 


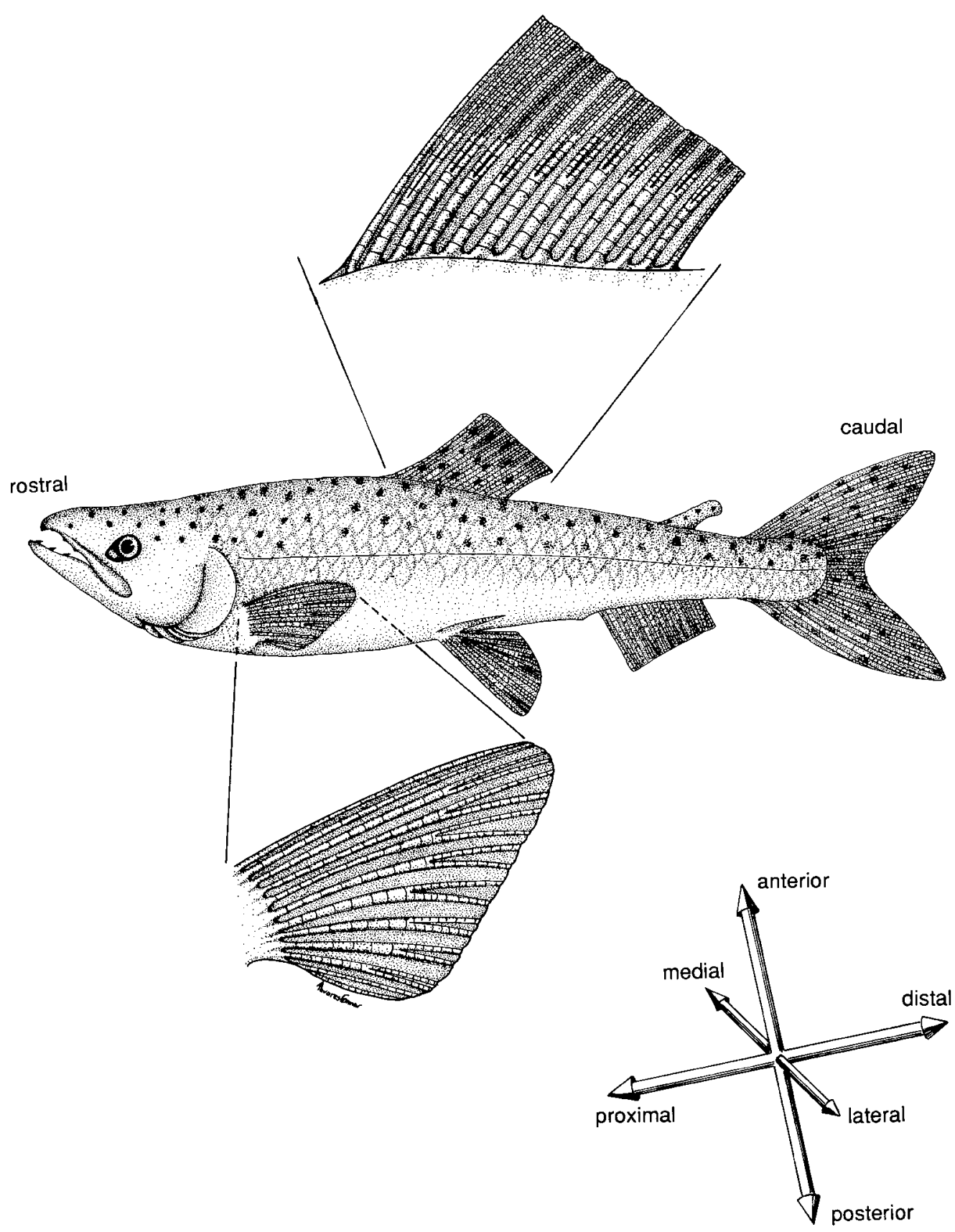

Fig. 1. Diagrammatic representation of the terms used with reference to the position and location of the fin-rays within the pectoral (lower enlargement) and dorsal (upper enlargement) fins of the chinook salmon, Oncorhynchus tshawytscha. (Modified from Geerlink, '89.)

ral and dorsal fins of the chinook salmon. These terms include anterior, posterior, proximal, distal, and medial and lateral. To further clarify these, "anterior" and "poste- rior" refer to the rays only, while the terms "rostral" and "caudal" refer to the fish as a whole. The terms "proximal" and "distal" will indicate the region of the ray closest to, 
or farthest from, respectively, the point of articulation of the fin to the body cavity. Rays are numbered starting from their most anterior position within the fin. The terms "medial" and "lateral" are defined in the following section on fin-ray morphology.

In scales, regular configurations or concentric ridges are referred to as circuli. These circuli are arranged in such a way as to form two distinct areas consisting of alternating wide and closely spaced bands. Zonation in other structures such as otoliths, dried finrays, vertebrae, and opercular bones refers to a difference in the degree of translucency or opacity of the particular tissue when viewed with specific forms of light. Translucent zones when observed using transmitted light appear bright in section (dark in reflective light) in contrast to opaque zones that appear darker (bright in reflective light). Annuli or yearly deposited rings are identified by abrupt changes associated with the relatively uniform appearance of the calcified tissue being examined. In scales, the annulus appears associated with an obvious break in the continuity in the configuration of circuli, and has often been referred to as a check. The annulus of other calcified structures is associated with the translucent zone. Checks or zones are usually formed prior to periods of reduced growth or cessation of growth (winter growth) and are separated by annuli from what is referred to as growth zones. These zones are associated with faster periods of growth (summer growth) and, in scales, appear as continuous, widely spaced circuli and in other calcified tissue as opaque zones (Casselman, '74, '83, '87). Since the annulus in this particular investigation is considered to correlate with a yearly event, the term band will be used to describe a concentric mark or feature deposited in the bone matrix.

\section{General morphology and arrangement of fin-ray components}

The number of fin-rays varied between 12-19 for the pectoral fin and 13-17 for the dorsal fin. A single fin-ray is actually composed of two parallel bony elements (Fig. $2 A$ ), often referred to by previous investigators as hemitrichia, hemisegments, or demirays (Lanzing, '76; Geerlink, '89). We use hemisegments with reference to the bony elements of both the pectoral and dorsal fins. Hemisegments are apposed to one another and are referred to as "medial" or "lateral" depending upon their position in the fin (Fig. 2A).

The following description includes diagrams and complementary light micrographs of tissue sections along the fin-ray ( $F$ igs. 2A-D, 3, 4). Hemisegments are constructed so that their shafts have an unsegmented proximal part and a flexible, segmented distal region. The latter area is composed of plate-like segments, which, upon macroscopic examination, appear as horizontal striations along thegreater part of the length of each ray. Proximal and distal units join together to form a single supporting rod, a hemisegment (Fig. 2A). When the fin was viewed in cross section, a channel of connective tissue was found between the concave surfaces of the crescent-shaped medial and lateral elements of each fin-ray. This region, referred to as the intersegmental region (Lanzing, '76), is characterized by the presence of nerve bundles, blood vessels, and fibrous connective tissue (Fig. 2A,D). Nerve bundles observed in this region consist of both myelinated and unmyelinated fibers enclosed by the cytoplasm of Schwann cells. Nearby blood vessels were identified as arteries and veins.

At their most proximal extremity, the pectoral rays are supported by the radial bones of the pectoral girdle. The distal scapular radial supports the anterior-most ray directly and four large radials support the remainder of the rays (Fig. 3). Hemisegments of the dorsal fin diverge at the distal

Fig. 2. A: Diagrammatic representation of medial (mh) and lateral (Ih) dorsal hemisegments in Oncorhynchus tshawytscha (modified from Lanzing, '76). The shafts of the hemisegments have an unsegmented proximal part that embraces the radial cartilage (c) and a flexible segmented distal region viewed as horizontal striations (arrows). The latter area is composed of platelike segments $(*)$. Transverse sections of the fin-ray reveal a channel of connective tissue, the intersegmental region $(I)$. Horizontal lines $(b, c, d)$ are approximate regions represented in subsequent micrographs (B-D).

B: Transverse section through the most distal aspect of the radials shown in $A$. Note the presence of adipose tissue (A) surrounded by bone (arrows). ct, fibrous connective tissue. C: Chondrogenic tissue (C) representative of the radial hyaline cartilage characterizes region I of the pectoral and dorsal fins. Bone tissue (arrows) is reduced from that demonstrated in $\mathbf{B}$. $\mathrm{M}$, muscle. $\mathbf{D}$ : Transverse section through the intersegmental region located between the concave surfaces of the crescentshaped medial (mh) and lateral (Ih) pectoral hemisegments. This region is characterized by the presence of nerve bundles (arrows), arteries (a), veins (v), and connective tissue (ct). Scale bars $=100 \mu \mathrm{m}$ for $\mathrm{B}, \mathrm{C}$, and D. 


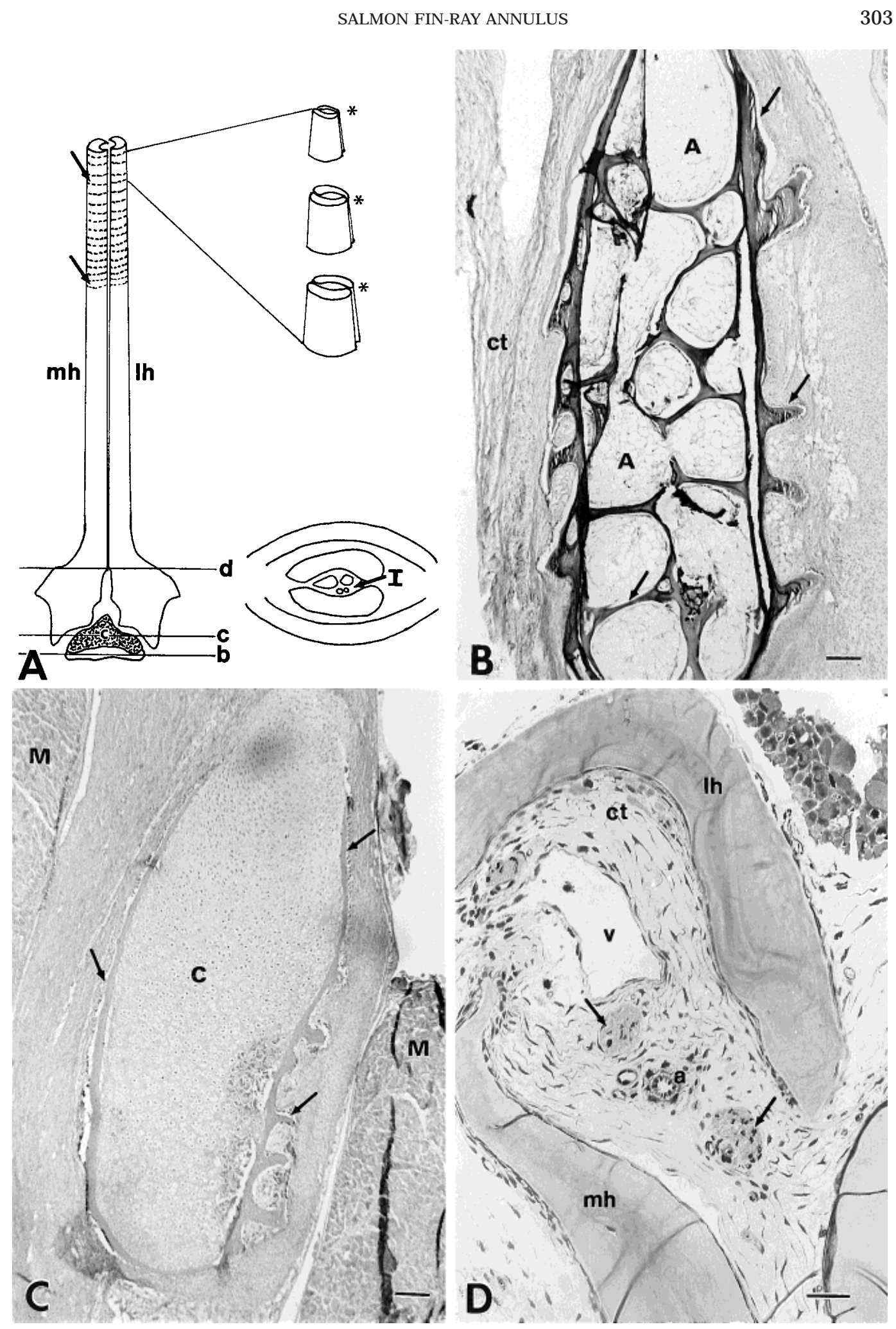

Figure2 

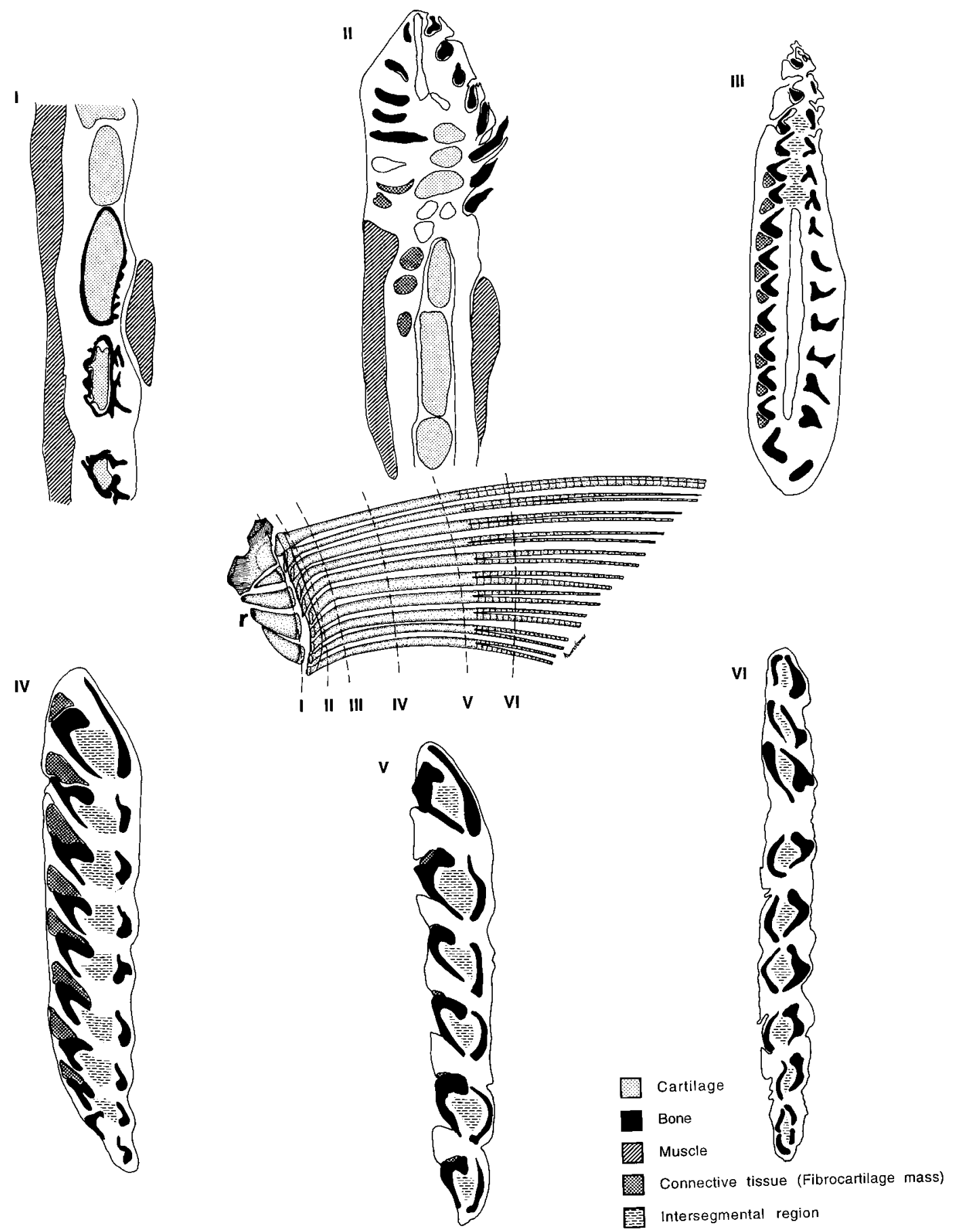

Fig. 3. Diagrammatic representation of the pectoral fin of the chinook salmon, Oncorhynchus tshawytscha, and its association with the underlying radials ( $r$ ). Views of transverse sections of the fin $(I-\mathrm{VI})$ along their long axis and the various shapes and types of tissue components are depicted. 

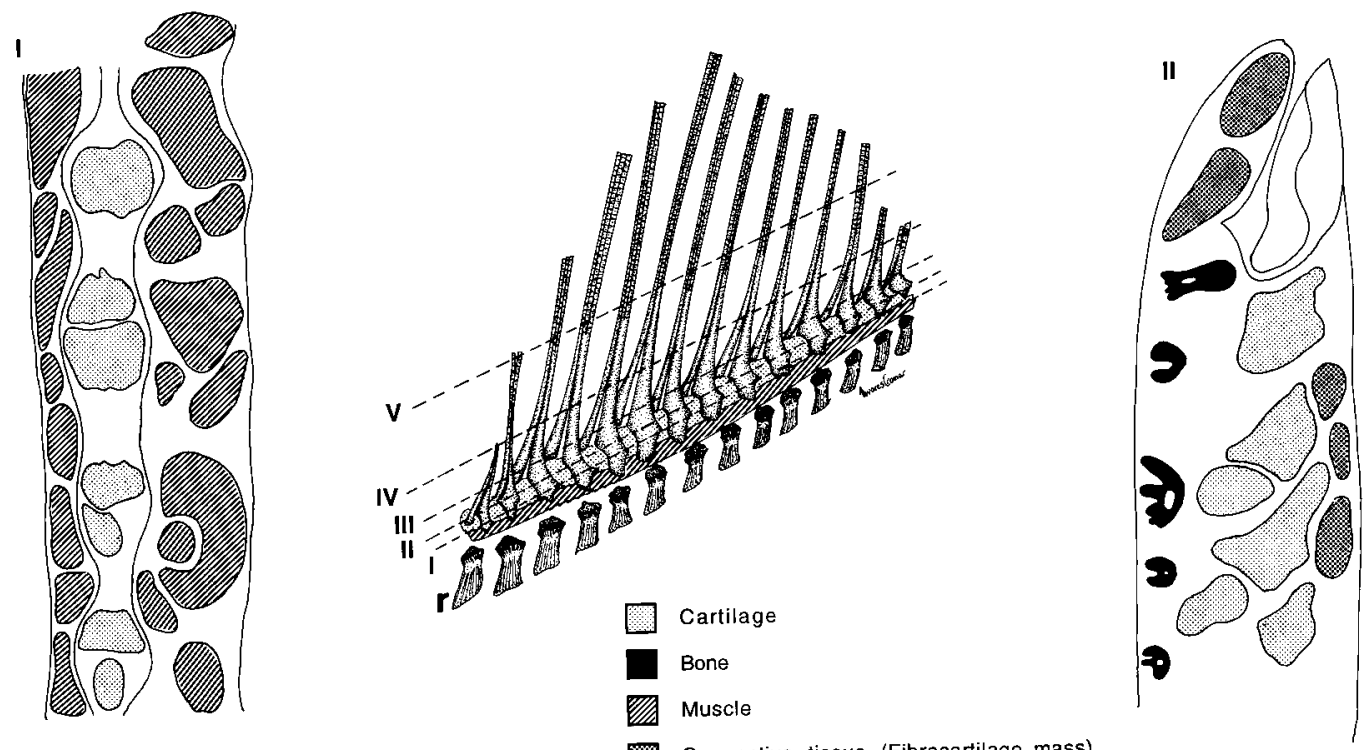

Connective tissue (Fibrocartilage mass)

Intersegmental region
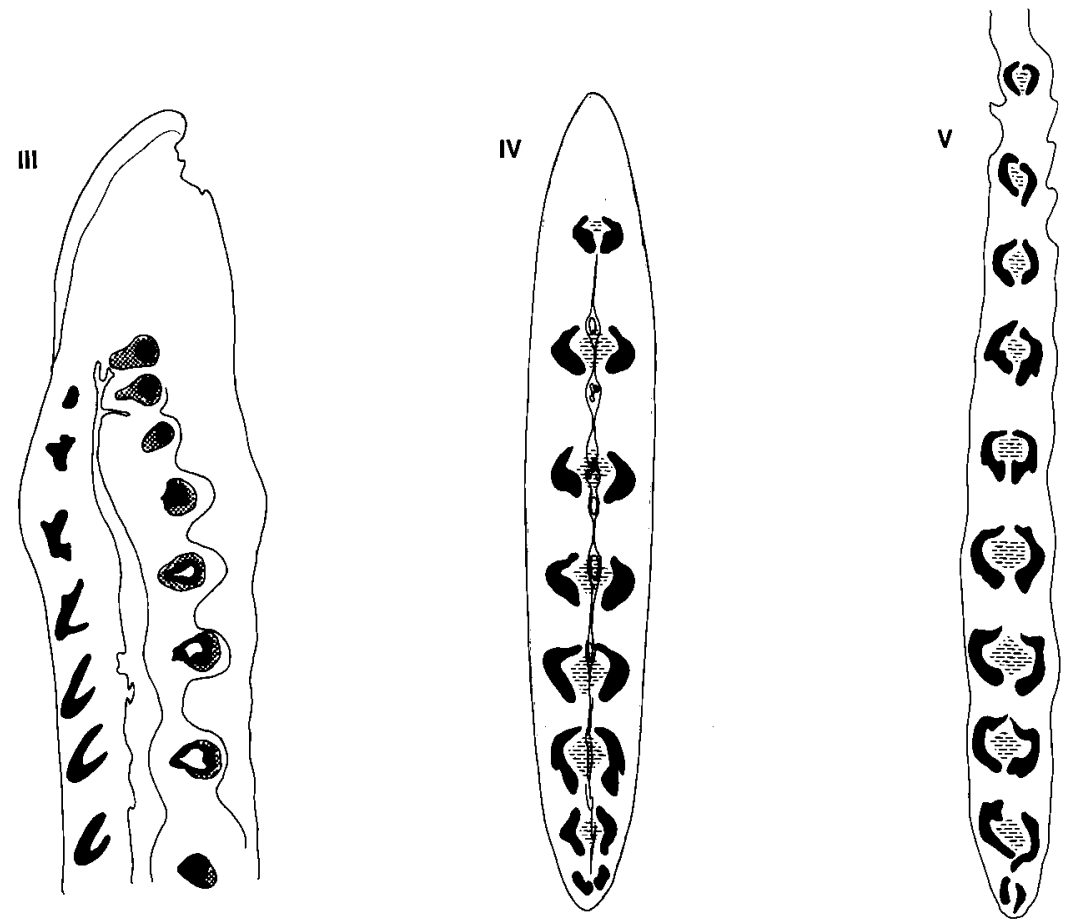

Fig. 4. Diagrammatic representation of the dorsal fin of the chinook salmon, Oncorhynchus tshawytscha, and its association with underlying radials $(r)$. Views of transverse sections of the fin $(\mathrm{I}-\mathrm{V})$ along their long axis and the various shapes and types of tissue components are depicted. 
margin of the endoskel etal radials (Figs. 2A, 4). F oll owing digestion of both fins with buffered trypsin, pectoral and dorsal hemisegments were observed embracing cartilaginous tissue overlying the radials (Figs. 3, 4). The radials articulate with the pectoral and dorsal hemisegments and they also articulate with the underlying pectoral girdle and vertebral column, respectively.

Thegeneral shape of hemisegments is variable along the length of the pectoral and dorsal fins. For this reason, both fins were divided into regions along their long axis. Each transverse serial section could then be classified into a specific region that would indicate to the reader from which area along the fin the section was taken. The reader is referred to a series of diagrams, presented in Figures 3 and 4 . Figure 3 illustrates six $(\mathrm{I}-\mathrm{VI})$ regionalized areas of the pectoral fin, whereas, five $(I-V)$ regions are demonstrated in the dorsal fin (Fig. 4). Light micrographs (Figs. 2B, 5B-8B) corresponding to the specific regions represented in the diagrams (Figs. 3 and 4), are used to clarify the components characteristic of each area. Diagrams and micrographs are used in conjunction with one another to describethese regions in detail below.

Region I of the pectoral fin is presented diagrammatically in Figure 3 (3I), and is represented in Figures $2 \mathrm{~B}$ and $\mathrm{C}$. Distinct, centrally positioned, groups of hyaline cartilage are characteristic of this region. In the corresponding stained tissue sections, the matrix of this cartilage appears strongly basophilic and chondrocytes form isogenous cell groups. Spicules of bone in the peripheral sections of this chondrogenic tissue represent the most distal aspects of the underlying radials (Fig. 2B). Region I of the dorsal fin represents the same area just above the point where rays embrace the cartilaginous pads of tissue belonging to the dorsal radials. The absence of bony tissue in this region of the dorsal fin (Fig. 4I) simply indicates that the level of sectioning of this fin began more distally than that of the pectoral fin. Cartilage was displayed as discrete groups of chondrogenic tissue bordered on either side by muscle (Fig. 4I).

Region II of the dorsal and pectoral fins demonstrates similar tissue components to region I and is representative of the rays just above their most proximal extremity. Pads of cartilaginous tissue are still present in these regions (Figs. 3II, 4II). Adjacent to the cartilaginous pads, are areas of dense connective tissue, of an uncertain nature, but that appear to be composed of fibroblasts and small groups of chondrocytes among numerous collagen fibers in both the dorsal (Fig. 5A,B) and pectoral (Fig. 5C,D) fins. Their appearance is characteristic of fibrocartilage tissue found in other vertebrates. For this reason, it was referred to as a "fibrocartilage mass." Sometimes an area of condensed, bony tissue is present within the fibrocartilage mass (Fig. 6A,B). We believe this bony element represents the most proximal portion of the hemisegment. I n the same region, dorsal fin hemisegments first appear on the medial aspect of the fin as irregularly shaped structures (Fig. 4II) and progress distally to an elongated form similar to that of the pectoral fins (Fig. 6C). It seems that the appearance of the medial hemisegment prior to those on the lateral side is due to length differences between the two hemisegments. The most consistent feature of regi on II in both fins is the presence of centrally located groups of hyaline cartilage, dense connective tissue areas that, more distally, appear to give rise to bony structures, and the continuously changing shape of fin-rays that are al ready visible.

Cross-sectioned, medial fin-ray elements of the pectoral fin, in regions III to $\mathrm{V}$ are roughly horseshoe shaped (Fig. 3III, IV, V) when compared with corresponding lateral hemisegments. Although, the latter vary considerably in their form, they are, for the most part, roughly crescent-shaped. We re fer to extensions of the main body of each hemisegment as "arms." Arms are further described as "major" or "minor" reflecting differences in size (Fig. 6D). The pectoral

Fig. 5. A: A transverse section through region II of the dorsal fin of an adult salmon, Oncorhynchus tshawytscha, representing the most distal aspect of the underlying radial cartilage. Directly adjacent to the pad of cartilage (C), are dense areas of connective tissue consisting of discrete masses of fibrocartilage (fm). B: High magnification of three fibrocartilage masses (fm) observed in A, showing their compact and hyalinized nature compared to the surrounding fibrous connective tissue (ct). C, hyaline cartilage. C: Transverse section of region II of the pectoral fin representing the distal extremity of the radials and showing an area of fibrocartilage (fm) tissue adjacent to the radial cartilage (C), muscle (M), adipose tissue (A), and bone (arrows). D: High magnification of fibrocartilage (fm) observed in C reveal ing cells (arrows) among numerous collagen fibers (arrowheads). A, adipose tissue; C, hyaline cartilage; M, muscle. Scale bars for $A$ to $D=100 \mu \mathrm{m}$. 


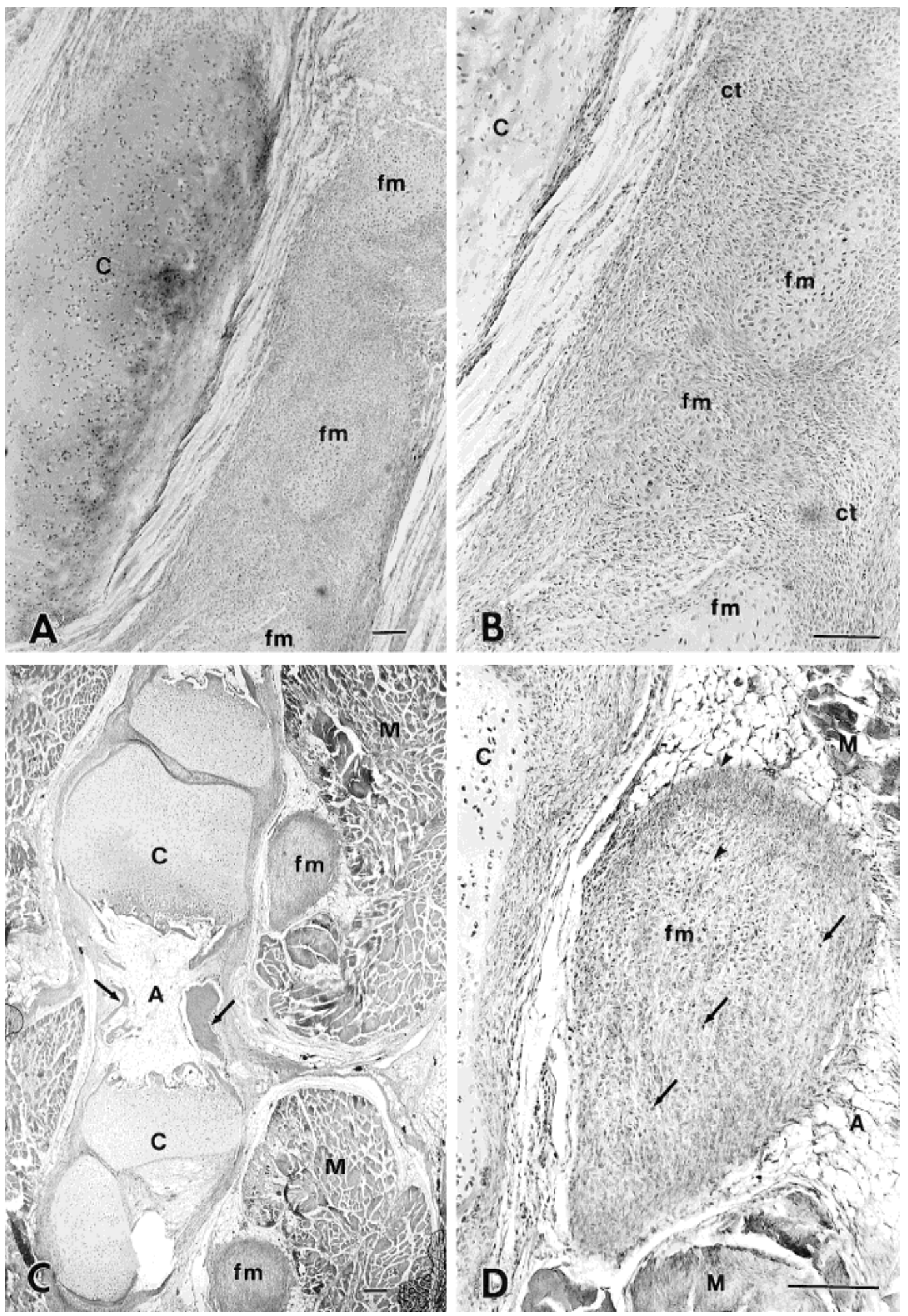

Figure 5 

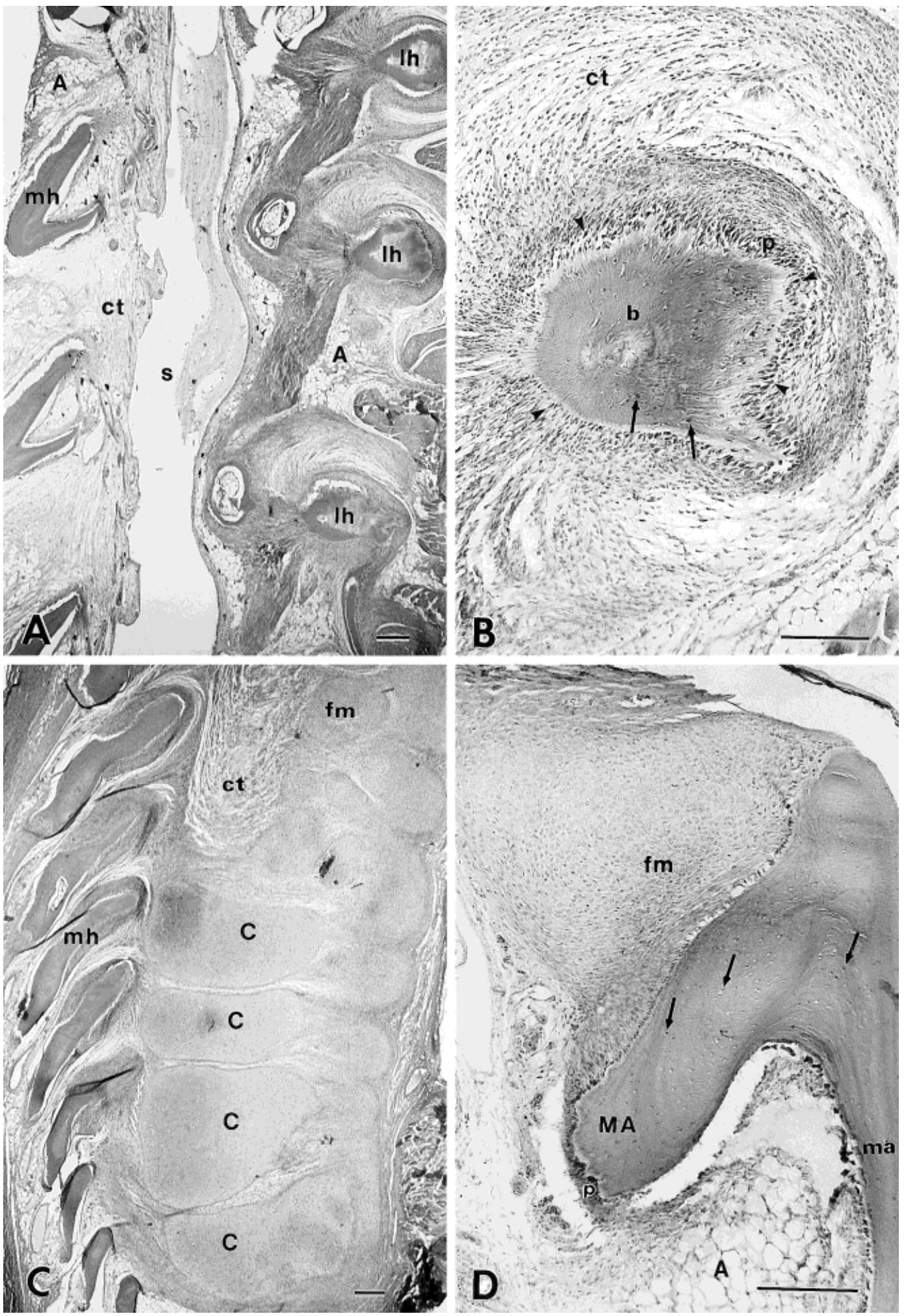

Figure 6 
arrangement of the two apposing hemisegments is asymmetric in these regions, since medial hemisegments arealways larger than lateral ones (Figs. 3III to VI, 7A-D). The major and minor arms of the medial hemisegment are more clearly defined than in the corresponding lateral hemisegments. In region III of the pectoral fin, a cone-shaped, well-delimited structure attaches to the outer medial hemisegment of each fin-ray (Fig. 6 D). This tissue appears similar to the "fibrocartilage mass" previously identified in region II. The fibrocartilage tissue consists of an extensive collagenous network surrounding small areas of hyaline cartilage and attaches to the medial hemisegment along a line where collagenous fibers penetrated the bone from the periosteal area (Fig. 7A,B). This basophilic mass appears to originate in the dermis at the proximal end of the fin and diminishes gradually towards the distal tip of the ray (Figs. 3IV, 7C,D). Theintersegmental region is not well developed in region III of the pectoral fins since the loss of cartilaginous elements results in a large space between apposing hemisegments (Fig. 3III).

The main difference in hemisegments in region IV of the pectoral fin from those of region III is a slight change in their shape. Rays are considerably larger in region IV and the intersegmental region between the apposing hemisegments is well vascularized with arteries and veins and contains bundles of nerve fibers, collagen fibers, and adipose

Fig. 6. A: A transverse section taken from the dorsal fin of an adult salmon, Oncorhynchus tshawytscha. This area represents the most distal aspect of region II and the most proximal aspect of region III. The medial hemisegments $(\mathrm{mh})$ are characteristically horseshoe shaped whilethelateral hemisegments (Ih) are observed as sites of condensed tissue. A space (s) is now in the area formerly occupied by the radial cartilages. $A$, adipose tissue; $c t$, fibrous connective tissue. B: High magnification of a lateral hemisegment in A. From the site of condensed tissue a definitive lateral hemisegment will develop through the process of periosteal osteogenesis. Note the presence of osteoblasts (arrowheads) in the periosteum (p) and osteocytes (arrows) surrounded by newly formed bone matrix (b). ct, fibrous connective tissue. C: Region II of the pectoral fin has radial cartilages $(\mathrm{C})$, el ongate medial hemisegments of bone $(\mathrm{mh})$ and fibrocartilage (fm). ct, fibrous connective tissue. D: A transverse section through the medial hemisegment in region III of the pectoral fin from an adult salmon. Note the major (MA) and minor (ma) arms and the cone-shaped, well-delimited fibrocartilage mass (fm) attached to the outer portion of the hemisegment. A, adipose tissue; $p$, periosteum; arrows, osteocytes. Scale bars for $A$ to $D=100 \mu \mathrm{m}$. tissue. In regions $\mathrm{V}$ and $\mathrm{VI}$ of the pectoral fin, the reduction in size of the fibrocartilage mass and theintersegmental region is apparent (Figs. 3V,VI , 7C,D). The medial hemisegments of these regions are less attenuated and smaller while the lateral hemisegments are el ongated and crescent-shaped.

Region III of the dorsal fin is characterized by well-formed medial hemisegments and adjacent connective tissue masses (Figs. 4I II, 6A). Medial hemisegments of the dorsal fin, as in the pectoral fin, are also horseshoe shaped. In addition, condensed tissue, likely bone, is apparent (Fig. 6B). In this region as well, a large space exists where cartilaginous elements had been present in more proximal areas (Fig. 4III), probably a consequence of tissue displacement during sectioning (Fig. 4III).

In region IV of the dorsal fin, hemisegments are symmetric in distribution and shape (Fig. 8A,B). Although nerves and blood vessels are present within the intersegmental regions, this area appears less vascularized than the corresponding region in the pectoral fin. Collagen fibers are al so present in the areas surrounding the hemisegments but the fibrocartilage mass observed in re gions III and IV of the pectoral fin is not present. Region $\mathrm{V}$ is characterized by reduction in size and shape of hemisegments with the lateral and medial hemisegments having a distinct $U$-shaped or arched appearance (Fig. $4 \mathrm{IV}, \mathrm{V}$ ).

\section{Fin-ray annuli}

Light microscopic preparations of transversely sectioned rays from adult tissue clearly demonstrate the presence of narrow dark (purple) bands alternating with wide light (purple) bands. This pattern was only visible when fins were fixed and decalcified simultaneously with Bouin's fixative and subsequently stained with Ehrlich's hematoxylin and an eosin counterstain ( $F$ ig. 8A,B). Initially various decalcifying agents were tested to determine which solution best de calcified the bone tissue in the least amount of time but still might express an alternate banding pattern. All efforts were made to ensure the size of the tissues were similar (3 $\mathrm{mm}^{3}$ ), that temperature remained constant, and that solutions were changed frequently. Compl ete decalcification was determined according to Clayden ('52) (see Materials and Methods) with the exception of those tissues demineralized in Bouin's fixative. In this 

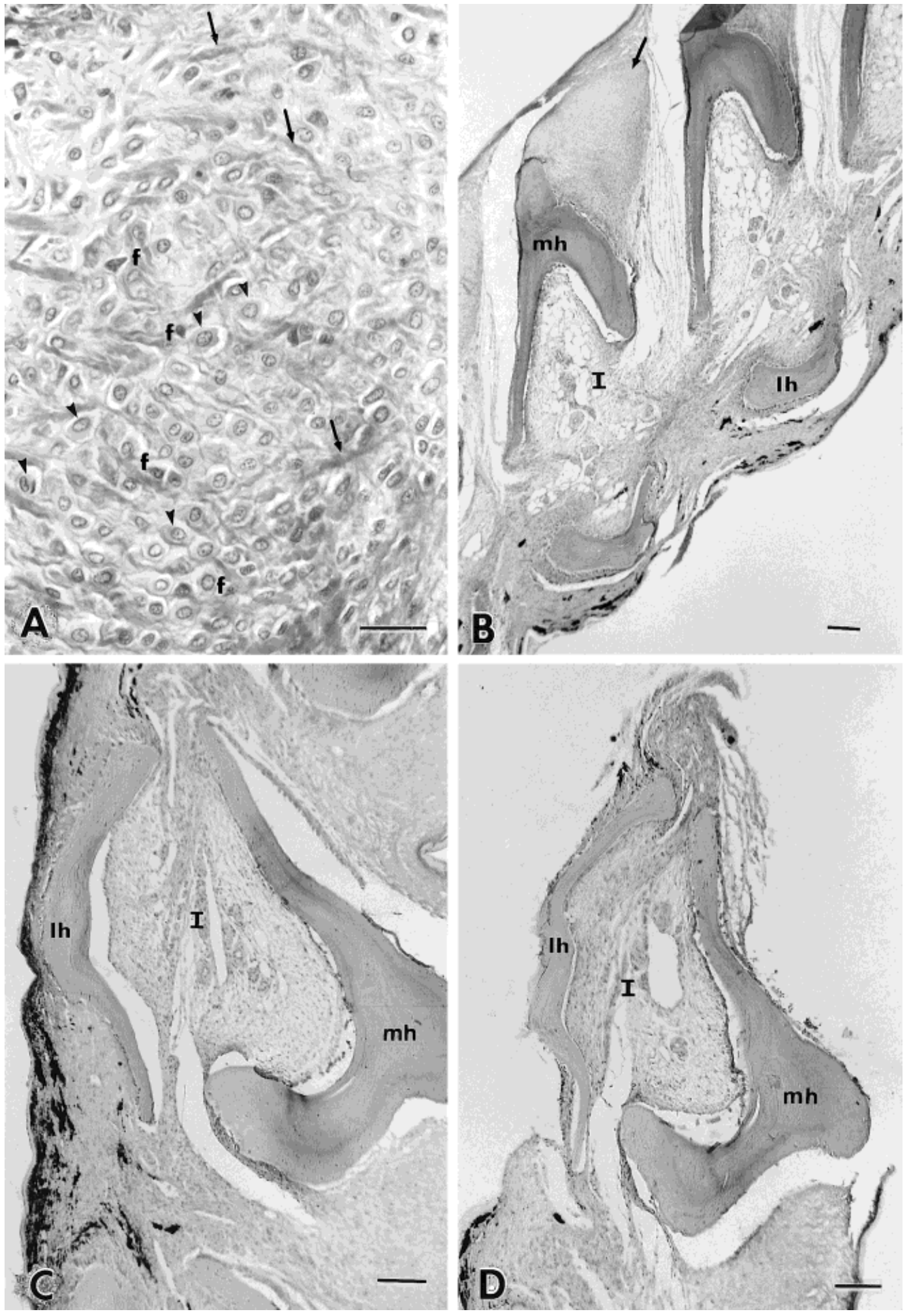

Figure 7 
latter case, the endpoint of decalcification was determined mechanically by piercing the bone with a pin. The data showed that the major factor responsible for the demonstration of these bands (when all tissues were stained with hematoxylin and eosin) was the Bouin's fixative and the length of time tissues spent in this solution. Bands were present in different sized adult tissues ( $3 \mathrm{~mm}^{3}$, single fin-ray, entire fin) fixed in Bouin's fluid for 60,93 , and 275 days, respectively. No bands were found in stained sections following fixation in $10 \%$ buffered formal in and decal cification in either nitric acid, formic acid, EDTA, Von Ebners, or RichmanGelfand-Hill solutions. It is also noteworthy that staining of discrete bands was not observed with any of the juvenile samples examined, even after extended exposure to the Bouin's fixative.

Alternating dark and light bands in adult samples corresponded to narrow translucent and wide opaque zones, respectively, when dried unstained sections were examined through transmitted light (Figs. 8C,D, $9 A, B)$. Since the annulus had been associated with the translucent zone of dried preparations (Casselman, '78) and the dark banding of the fixed, stained tissue coincided with this translucent area, the dark bands were recognized as annuli. In most cases, several dark bands, grouped together in stained preparations corresponded to a single translucent zone. Bands were present in the form of opaque and translucent zones when back-scatter SEM was used (Fig. 9C). In general, the opaque zone was approximately four times greater than adjacent translucent zones.

Fig. 7. Fins of chinook salmon, Oncorhynchus tshawytscha. A: High magnification of the cone-shaped mass observed in Figure 6D. This tissue resembles the fibrocartilage masses described in region II and consists of an extensive network of collagen (arrows), fibroblasts (f), and chondrocytes (arrowheads). B: Light micrograph of the horseshoe shaped medial (mh) and the crescent shaped lateral (Ih) hemisegments in region IV of the pectoral fin. A dense cord of fibrocartilage tissue (arrow) attaches to the outer edge of the medial ray and an intersegmental region ( $\mathrm{I}$ ) is present between thehemisegments. C: A transverse section through region $\mathrm{V}$ of the pectoral fin showing a less attenuated medial hemisegment (mh), more elongate lateral hemisegments (lh), and a reduced intersegmental region (I). D: Region VI is characteristic of the distal portion of the pectoral fin and shows elongated medial ( $\mathrm{mh}$ ) and lateral (Ih) hemisegments with an intervening intersegmental region. Scale bars for $A=50 \mu \mathrm{m}$, for $B-D=100 \mu \mathrm{m}$.
Staining methods, other than hematoxylin and eosin, were utilized in an attempt to elucidate the structural composition of the annulus. Sections of bone decalcified in Bouin's fixative were stained specifically for the presence of DNA using Feulgen's stain, collagen using Masson's trichromestain, and simple polysaccharides of the ground substance (glycosaminoglycans) using the periodic acid-Schiff technique. Only tissues stained with hematoxylin and eosin demonstrated a banded appearance, indicating that these bands were not composed of polysaccharides or DNA. Although banding was absent with the Masson's trichrome procedure, the entire matrix stained homogeneously for collagen.

Banding of hemisegments appeared along the entire length of the ray throughout all the regions outlined above but often the staining intensity of these bands varied. In many instances, the central (core body) and peripheral (beneath the periosteum) bands stained darker than bands found in other regions of the matrix (Fig. 10A). Not only was stai ning inconsistent, but the number of bands also varied between individuals and between the regions examined. Banding was present in the most proximal aspect of the rays in regions II and III. As the distal aspects of the hemisegments were approached in regions IV, $\mathrm{V}$, and $\mathrm{VI}$ of the pectoral fins and in regions IV and $V$ of the dorsal fins, the number of bands was reduced. In many cases, only the core body was observed in these regions, appearing as a bilaterally curved structure close to the periphery of the ray (Fig. 10B,C). Region IV of the medial hemisegment in the pectoral fin displayed the greatest number of bands throughout the entire ray. Up to twelvebands were counted on the major arm of one particular fin-ray from a four-year old salmon (Fig. 10C). In general, the number of bands was greater in the medial hemisegments of the pectoral fin than in the medial hemisegments of the dorsal fin. In many cases, the variance in band number may have been due to the differing ages of the individuals when the fins were removed. An individual that was determined as being 2 years old usually exhibited a number of bands grouped together (annuli), usually in the central and peripheral areas of the ray. This banding in turn, corresponded to two translucent zones in dried fins (Fig. 9A,B). A fish that was 3 years of age displayed an additional series of 


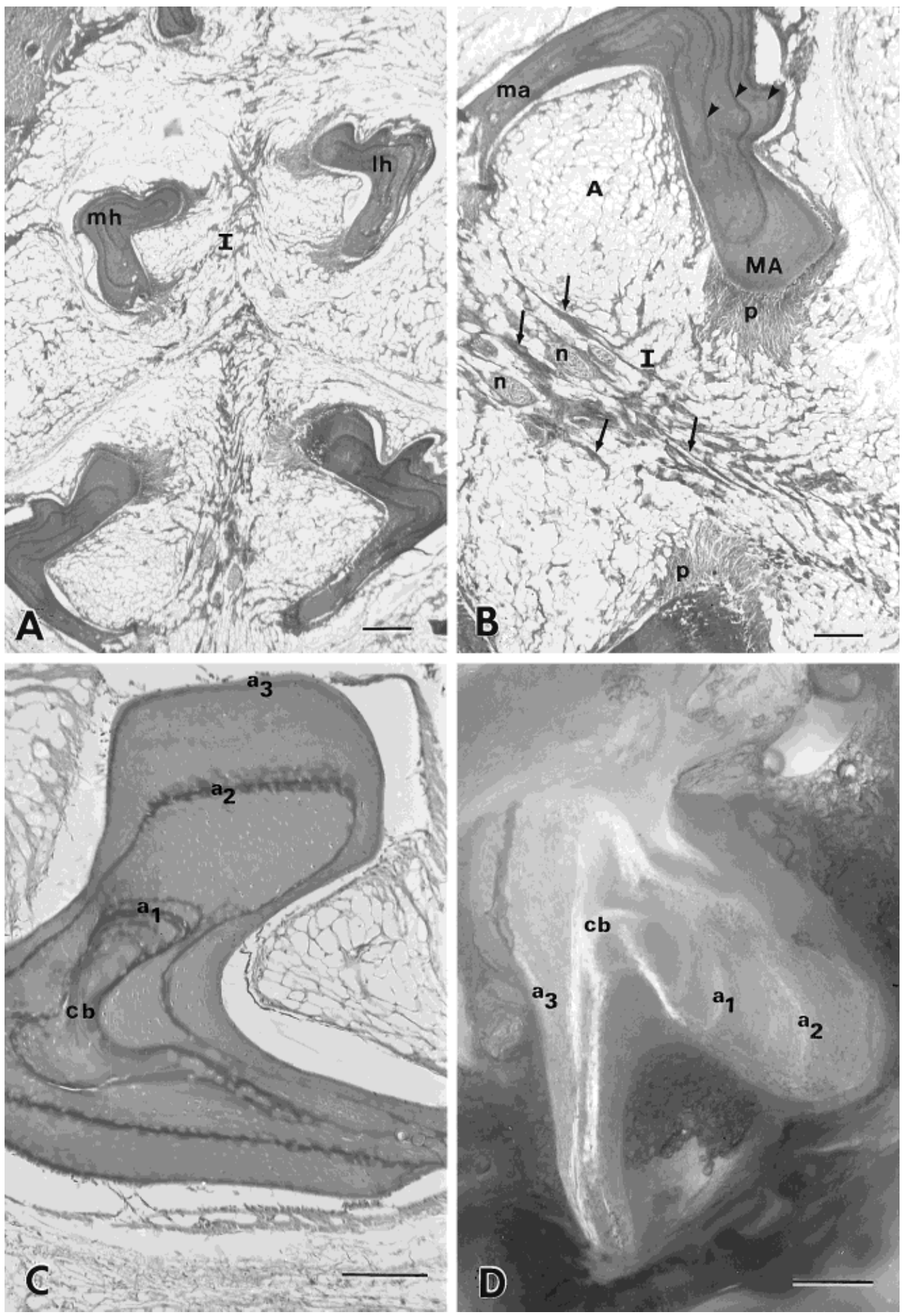


bands when compared to 2-year-old individuals (Fig. 8C,D). I n this case, dried fin samples exhibited a third translucent zone (Fig. 8D). Even when rays were sectioned longitudinally or obliquely, they continued to demonstrate groups of dark bands whose numbers were indicative of the age of the animal .

\section{DISCUSSION \\ Morphology of the fin-ray \\ of the chinook salmon}

This study demonstrates that the number and arrangement of rays in both pectoral and dorsal fins, and their association with the underlying radials are consistent with previous descriptions (Hikita, '62) on fin-ray morphology in the genus Oncorhynchus (Salmonidae). Many of the morphological features documented in studies of the threedimensional organization of fin-rays within the fins of various chordate species (Arita, '71; Lanzing, '76; Potthoff and Kelley, '82; Geerlink, '89; Holland and Holland, '91), were al so observed in the fins of the chinook salmon. However, the present study provides new insight into the histol ogical structure of the salmon fin-ray.

The cartilaginous areas that appeared in regions I and II of the pectoral and dorsal fins have also been described in other species of Pacific salmon as a pad of subcartilaginous tissue intercalated between the bones of the radials and the proximal ends of the fin-rays (Hikita, '62). In the current study, the diverging halves of each ray were observed to embrace this pad of tissue at the extremities of the scapula and the four radi-

Fig. 8. Fins of chinook salmon, Oncorhynchus tshawytscha. A: Transverse section of the dorsal fin representative of region IV. Note the symmetrical shape of medial $(\mathrm{mh})$ and lateral $(\mathrm{lh})$ hemisegments and the presence of an intersegmental (I) region. B: High magnification of a region in A demonstrating two opposing hemisegments. The intersegmental region (I) consists of nerve bundles ( $n$ ), collagen fibers (arrows), and adipose tissue (A). At the tips of the major arm (MA) the periosteum (p) is visible and annuli (arrowheads) are also present. ma, minor arm. C: Light micrograph of a medial hemisegment removed from the pectoral fin of a 3-year-old salmon and stained with Ehrlich's hematoxylin and an eosin counterstain. The presence of three distinct, darkly stained bands (annuli) are observed $\left(a_{1}, a_{2}, a_{3}\right)$. The core body $(\mathrm{cb})$ is located in the central region of the ray. $\mathbf{D}$ : Dried preparation of a medial hemisegment corresponding to $\mathrm{C}$. Both rays were removed from the same fish. Note the presence of alternating wide opaque and narrow translucent bands. The latter type represents annuli. Three annuli $\left(a_{1}, a_{2}, a_{3}\right)$ are visible. $c b$, core body. Scale bars for $A=200 \mu \mathrm{m}$, for $B-D=100 \mu \mathrm{m}$. als of the pectoral fin, and the radials of the dorsal fin. This same arrangement of finrays to radial cartilages exists in the pectoral fins of blennies (Brandstatter et al., '90). The pectoral fins of Coris formosa also have an elongated fibrocartilage pad into which the distal ends of the radials fit and each base of the medial and lateral hemisegments articulate (Geerlink, '83). The latter fibrocartilage structure resembles the subcartilaginous pad described earlier in salmon. In the dorsal fins of tuna and swordfish, similar cartilaginous elements of the underlying radials have been described as articulating with the proximal ends of the overlying hemisegments (Potthoff, '74; Potthoff and Kelley, '82).

The fin-rays of chinook salmon are constructed so that each hemisegment has an unsegmented proximal part and a flexible distal region, consisting of small plate-like segments. This structural composition has been observed in the fin-rays of many fishes (Arita, '71; Lanzing, '76; Brandstatter et al., '90) and is consistent with the definition of a soft ray (Prince and Pul os, '83). It is believed that this construction permits bending of the rays (Geerlink and Videler, '87).

The fibrocartilage mass, attached to the outer edge of the medial hemisegment, is an unusual feature present only in regions III and IV of the pectoral fin. A similar structure, referred to as the lepidotrichal cord in blennies, is also located along the free edge of the outer medial hemisegment gradually diminishing towards the distal tip (Brandstatter et al., '90). The lepidotrichal cord is composed of fibrocytes, collagenous fibers, elastic fibers, and an alcian blue-positive extracellular matrix. It has been suggested that it contributes to the stiffness of the bony fin-rays. Since in chinook salmon the fibrocartilage mass occurs only in the proximal portions of the medial ray, this structure may also impart stiffness to this region of the fin-rays. That these masses are not present in dorsal fins may be a reflection of functional differences in the various fins. It has been documented that pectoral and pelvic fins act as swim paddles whereas the dorsal fin may act only to align the fish in its movements (Romer and Parsons, '86).

The histology and ultrastructure of mammalian bone have been well documented (Cameron, '72; Robinson et al., '77), providing most of the information that exists on the structure of vertebrate bone. Prior to the 

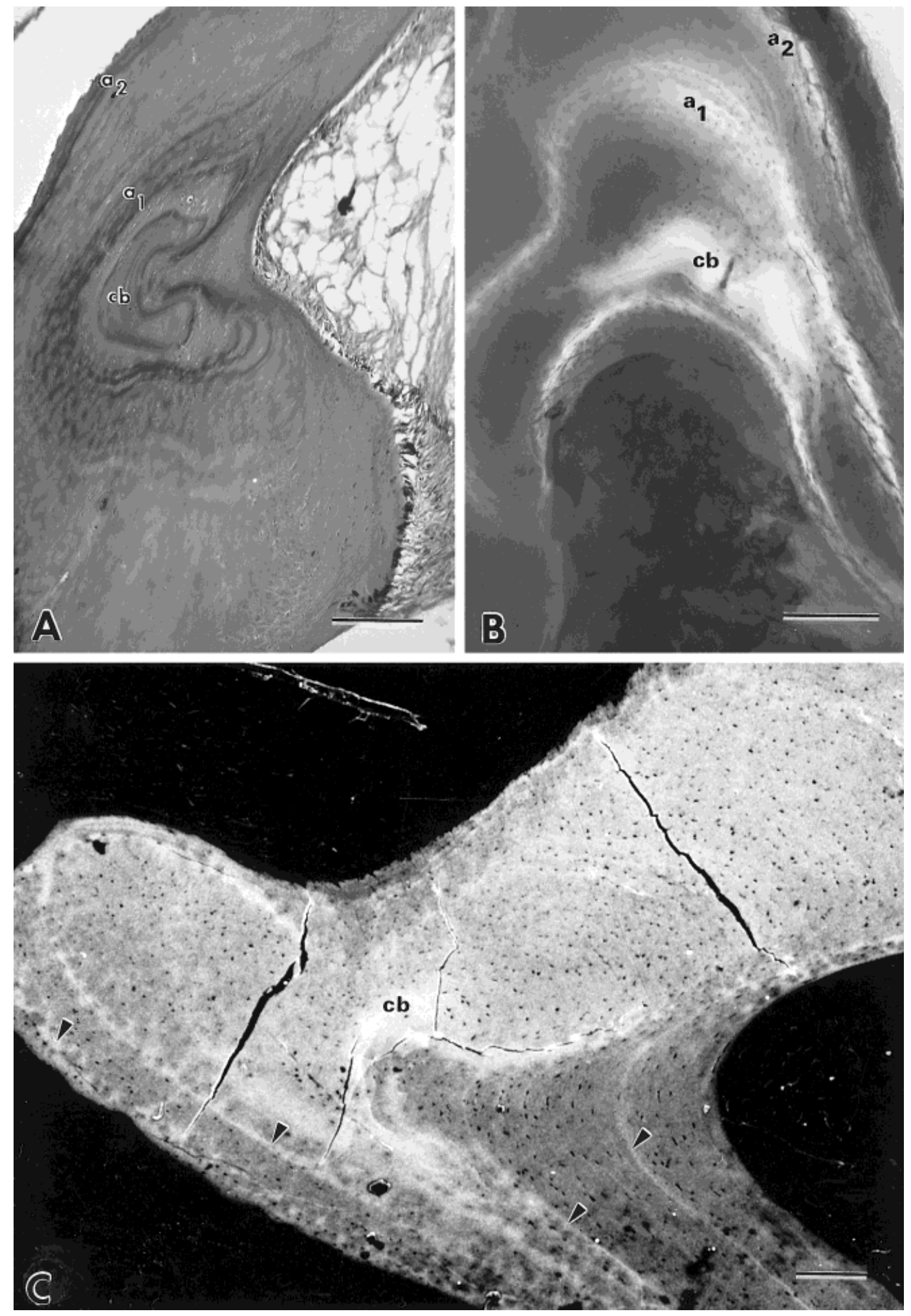

Figure 9 
present study on the nature of demineralized bone of chinook salmon fin-rays, few studies had focused on the histological structure of teleost bone or on its mode of development. Moss ('61a,b, '63), and more recently Weiss ('78), provided the most comprehensive studies on teleost bone. Histological studies of teleost bone have demonstrated that bone forms beneath periosteal tissue and endosteal tissue within a cartilaginous matrix (Norris et al ., '63). These sites of bone development coincide with three distinct anatomic types of bone, namely, primary bone (non-lamellar), endosteal or secondary bone (lamellar), and endochondral or trabecular bone. Our companion study uses etching techniques and extracellular matrix digestion in conjunction with both scanning and transmission electron microscopy to describe the nature of the bone in the fin-rays of chinook salmon. In addition, the companion study shows that the bone in fin-rays of chinook salmon forms through periosteal osteogenesis and that the presence of enclosed osteocytes within the matrix, may suggest that this piscine bone is a cellular (osteocytic) type. However, the present study also provides some evidence of periosteal osteogenesis and also of bone formation from prechondrogenic precursors in region I of the pectoral fins in the chinook salmon. This area likely represents the most distal aspect of the cartilaginous joints of the underlying radials. The identity of cartilage was clearly demonstrated in whole fins from enzyme digestion, clearing techniques, and alcian blue. Previously, Geraudie and Landis ('82), when describing the embryonic development of the pelvic fin of trout, stated that radials devel op from an underlying cartilaginous girdl ethat stains with alcian blue. This

Fig. 9. A: Light micrograph of a medial hemisegment, removed from the dorsal fin of a 2-year-ol d salmon, Oncorhynchus tshawytscha, demonstrating alternating dark and light bands following hematoxylin and eosin staining. The core body (cb) and two annuli $\left(a_{1}, a_{2}\right)$ are present. B: This micrograph demonstrates a dried, unstained medial ray in transverse section, viewed through transmitted light. Narrow translucent and wide opaque zones correspond to dark and light bands viewed in A, respectively. The core body $(c b)$ and two annuli $\left(a_{1}, a_{2}\right)$ are visible. Scale bar = C: Backscatter scanning electron micrograph demonstrating translucent and opaque zones within the cross-sectional surface of a hemisegment. Translucent areas (arrowheads) were considered to be analogous to the annuli described in other preparations of fin-ray bone. $\mathrm{cb}$, corebody. Scale bars for A and $B=100 \mu \mathrm{m}$, for $C=25 \mu \mathrm{m}$. cartilaginous girdle is considered analogous to the subcartilaginous tissue described in other Pacific salmon (Hikita, '62) and to the cartilage tissue observed in region I of the pectoral and dorsal fins of the chinook salmon.

In the current study, the presence of hypertrophic chondrocytes within the cartilaginous matrix and the surrounding bone tissue in region I of the pectoral fins implies that radials devel op through a process resembling endochondral ossification. A similar developmental process, chondroid osteogenesis, has al so been described in the articular areas of the head in bony fishes (Moss, '61b). These areas are considered similar to mammalian epiphyseal cartilage where mineralization is achieved through the deposition of calcium salts following cell hypertrophy of chondroid tissue. The resulting tissue has been described as intermediate in form between notochordal tissue and hyaline cartilage.

Similar areas of cartilaginous tissue are present in region I of the dorsal fin; however, unlike region I of the pectoral fin, spicules of bone tissue, representing the underlying radials, were not observed. The different profiles in region I of the pectoral and dorsal fins may be explained by the way in which the dorsal fin was removed from the adjacent body cavity or simply may be due to the level at which sectioning of the fin began.

Hemisegments were first observed in re gion II of the pectoral and dorsal fins adjacent to the cartilaginous joints of the underlying radials in dense masses of what appeared to be fibrocartilage tissue. Although there is no documented evidence suggesting that bone formation occurs from fibrocartilage, these areas nevertheless appear to offer the appropriate environment for the initial sites of hemisegment development. The cytoplasmic basophilia of cells surrounding small spicules of bone in region II of the pectoral fin and regions II and III of the dorsal fins implies osteoblastic activity in synthesis of protein necessary for the proteoglycan component of bone. This activity would result in the initial formation of ray elements through periosteal osteogenesis. Since teleost bone of periosteal origin is re ferred to as primary or fibrillar bone (Norris et al., '63), this view of periosteal osteogenesis is reinforced by the presence of an abundance of collagenous fibrils within these re gions. According to Moss ('61b), during 

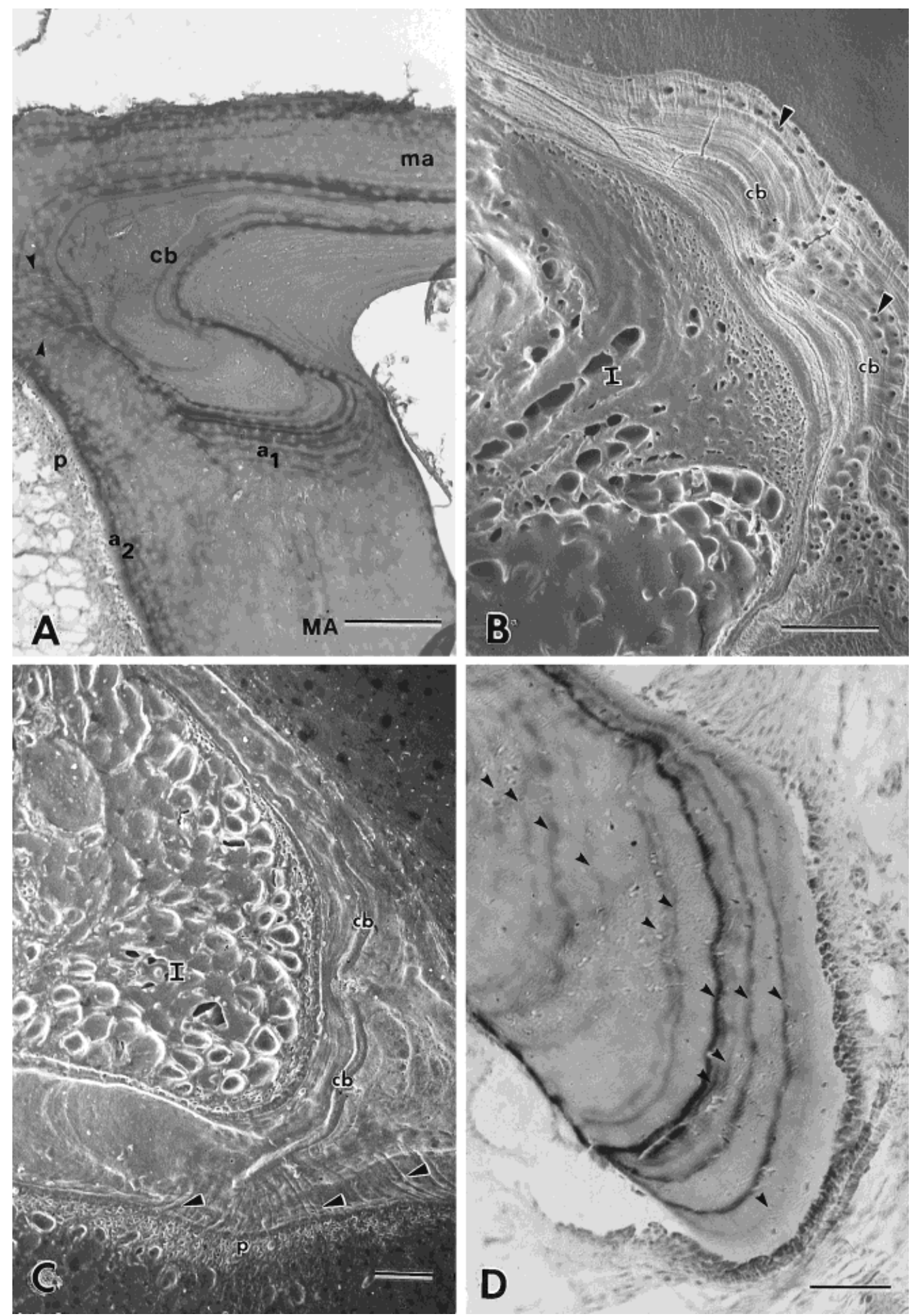

Figure 10 
periosteal osteogenesis in fish, osteoblasts aid in the production of consecutive layers of bone by the deposition of collagen fibrils.

Periosteal osteogenesis is considered the major mode of bone development in teleosts (Moss, '61b). Evidence of this type of bone development has also been documented in embryological studies on the pectoral, pelvic, and caudal fins of rainbow trout, Oncorhynchus mykiss. Fin-ray ontogenesis occurs by direct mineralization of the collagenous basal Iamella of the skin without passage through a cartilaginous precursor (Geraudie and Landis, '89). In an earlier embryological study of pelvic fin development in trout, hemisegments were stained with alizarin red but not with alcian blue (Geraudie and Landis, '82). Since alizarin red stains specifically for bone, they concluded that these dermal structures arose without an endochondral sequence. These reports, when considered in conjunction with our present observations, strongly suggest that endochondral ossification or chondroid osteogenesis does not play a rolein the development of fin-rays in chinook salmon, since we observed fin-rays arising from the activity of osteoblasts. Thus, the mode of fin-ray development differs from that of radial formation, since the latter appears to arise from cartilaginous tissue.

According to Landis and Geraudie ('91), after fin-ray devel opment commences in the pectoral fin, elongation of the bony rays is

Fig. 10. A: Light micrograph from region IV of a medial pectoral hemisegment, demonstrating the distinct banding pattern of fin-rays in the salmon, Oncorhynchus tshawytscha. The core body (cb) follows the shape of the ray and is surrounded by a number of closely packed bands representing the first annulus $\left(a_{1}\right)$. Another group of bands is directly beneath the periosteum $(p)$ and represents the second annulus $\left(a_{2}\right)$. Fine fracture lines extend from the core body to the periosteum (arrowheads). MA, major arm; ma, minor arm. B: Region $\mathrm{V}$ of a lateral hemisegment from the dorsal fin. This tissue was etched with EDTA followed by $\mathrm{NaOCI}$. SEM. Note the double-arched shape of the core body (cb). I, intersegmental region; arrowheads, lacunae of osteocytes. C: Region IV of a medial hemisegment from the dorsal fin. SEM. This ray was etched with Baxter decalcifying solution.The core body (cb) appears as a bilaterally curved structure. p, periosteum; I, intersegmental region; arrowheads, core body fibers. D: A transverse section through region IV of a medial hemisegment in the pectoral fin. Pectoral rays examined from this region consistently displayed the greatest number of bands throughout the fin. Twelve bands (arrowheads) were counted on the major arm of this 4-year-old salmon. Scale bars for $A=100 \mu \mathrm{m}$, for $B, D=50 \mu \mathrm{m}$, and for $C=$ $25 \mu \mathrm{m}$. achieved by the successful addition of new calcified segments at the distal end. Other investigators have documented this mode of development in the dorsal fins of fish (Potthoff, '74; Potthoff and Kelley, '82). Thus, the first ray elements to be formed would be observed in the most proximal areas of the fin.

\section{Annulus}

We demonstrated alternating dark and light purple bands following tissue exposure to hematoxylin and eosin. If we relate these bands to the optical zonation pattern demonstrated in prepared dried fin tissue, a number of dark bands correspond to a translucent zone and each light band to an opaque zone. Although oxytetracycline labelling of chinook salmon fin-rays has not been performed, the number of translucent zones correspond to the age of fish as determined by the time they were tagged as smolts (Beamish, unpublished data). Therefore, the groups of dark bands we revealed by this staining procedure each represent an annulus.

The presence of collagen in the annuli was verified using Masson's trichrome stain. Since fin-ray tissue failed to react with Feulgen's stain and the periodic acid-Schiff method, we believe that nucleic acids and polysaccharides, respectively, are not components of the annulus. In routine hematoxylin and eosin preparations, collagen is normally acidophilic, i.e., eosinophilic, in nature. However, often after long-term exposure of adult sal mon fin-rays to Bouin's fluid, hematoxylin stained specific portions (annuli) of the fin-ray intensely as compared to the intervening areas. This staining pattern may be due to the orientation of the fibers in the annulus and their closely packed arrange ment. Possibly, ions of the dye molecule (he matoxylin) become trapped between the fibers of this area and are not easily removed during subsequent washing procedures. This hematoxylin staining would result in the failure of the eosin to stain the collagen. Unlike the core body of adults, the core body of juveniles, however, did not stain with hematoxylin and eosin. This difference among developmental stages may suggest that the above postulate of fiber orientation affecting staining properties and intensity is not entirely the case. An alternative view is that calcium has not been totally removed from the bone of the adult fin-ray. With hematoxylin and eosin stains, most calcium salts 
are colored a deep blue-purple (Sheehan and Hrapchak, '80). Since X-ray microanalysis infers that translucent areas possess relatively more calcium (Cassel man, '78), these areas would stain moreintensely with hematoxylin than adjacent regions. Similar findings have also been documented in teeth that are decalcified and stained with hematoxylin and eosin (Schour and Hoffman, '49). This latter study assumed that hematoxylin stained well-calcified tissue more intensely in decalcified preparations. This hypothesis might better explain the failure of the core body of juveniles to stain. Animals were still quite young and possibly there was less calcium per unit area than was found in adult fin-ray bone. Calcium ions, therefore, may have been easily removed and, thus, bone of the juvenile fin-rays would not stain as readily with hematoxylin.

Staining and differentiation were also influenced to a great extent by the fixation/ decalcification method. Differential staining, i.e., banding, did not occur with tissues decalcified with EDTA, nitric acid or formic acid, suggesting that the prol onged decal cification of fin-ray tissue in Bouin's fixative may have accounted for the banding pattern observed in the current study. Fixation causes an increased affinity of proteins such as collagen for stains because as peptide chains unfold, secondary groups become availablefor the reaction with dye molecules (Padykula, '88). It is possible that the prolonged exposure of fins of adult salmon to Bouin's fixative and more specifically picric acid may havealtered the isoel ectric point of collagen to such an extent that it reacted with an affinity to the cationic ions of hematoxylin. Although, juveniles were also placed in Bouin's fixative for prolonged periods of time, the period was not as protracted as that of adult fins and this variable may account for the discrepancy in staining of bone between the two life cycle intervals.

The trends postulated above are confirmed when they are related to the results obtained directly from the backscatter analysis of the fin-ray tissue. Resembling images of mi croradi ographs, darker-grey level areas represent tissue that contains a lower mineral content and lighter-grey level tissue that contains a higher mineral content (Reid and Boyde, '87; Grynpas and Hol myard, '88; Boyce et al., '90; Skedros et al., '91). The lighter-grey level areas are represented as narrow bands located between much wider darker-grey level areas. These areas correlate well with the narrow translucent (annuli) and wide opaque zones of dried fin-ray tissue and, therefore, these areas almost certainly represent regions of high and low levels of cal cium, respectively.

Calcium values determined by line-scan analysis across cross-sectional slices of cod otoliths also indicate that the calcium content is higher in the translucent than in the opaquezone. Mugiya ('66) reported that during the period of opaque zone formation in flatfish, the diffusible cal cium in otolith fluid decreases to $65.4 \%$ of the total calcium, but reaches a maximum of $79.1 \%$ during the period of translucent zone formation (cited by Casselman, '78). I $\mathrm{n}$ acid-etched otoliths of laboratory fish, the translucent zones correspond with well-defined rings while the opaquezones are poorly etched (Taubert and Coble, ${ }^{777) . ~ S i m i l a r ~ f i n d i n g s ~ w e r e ~ o b s e r v e d ~}$ when EDTA was used for the etching (Gauldie and Nel son, '88). These results correlate well with the observations of the present study as we noted that elevations of fin-ray tissue are located in regions that correspond to translucent areas of dried tissues.

\section{CONCLUSIONS}

The present light microscopic study provides a detailed morphological description of the fin-ray of chinook salmon and indicates that transverse, stained sections of the finrays are useful indicators of age. In addition, the nature of the response to various decalcification agents and subsequent staining has provided some indication of a differential organization of extracellular matrix components between lamellae of the bone, namely fibrous and inorganic components. We suspect that this varied organization accounts for the marked appearance of annuli relative to intervening lamellae. Fine structural observations are required to confirm this supposition.

\section{ACKNOWLEDGMENTS}

This study was supported by a Science Subvention Grant from the Department of Fisheries and Oceans, Canada, and the Natural Science and Engineering Research Council of Canada (NSERC) and an NSERC operating grant to] .H.Y. The authors appreciate the technical hel p provided by D. H olmyard, R. Or, R. Roopsingh, G. Taylor, and S. Zaks. C. Neville and A. Thompson assisted in animal and tissue collection. 


\section{LITERATURE CITED}

Arita GS. 1971. A re-examination of the functional morphology of the soft-rays in teleosts. Copeia 1971:691697.

Baserga R, Malamud D. 1969. Modern methods in experimental pathology. Autoradiography. techniques and applications. New York: Harper and Row, p 129-146.

Boyce TM, Bloebaum RD, Bachus KN, Skedros J G. 1990. Calibration of the backscattered electron signal for bone, biomaterial and implant research. Sixteenth Annual Meeting of the Society for Biomaterials. May 20-23. Charleston, SC. p 188.

Brandstatter R, Misof B, Pazmandi C, Wagner GP. 1990. Micro-anatomy of the pectoral fin in blennies (Blenniini, Blennioidea, Teleostei). J Fish Biol 37:729-743.

Cameron DA. 1972. Theultrastucture of bone. I n: Bourne $\mathrm{GH}$, editor. The biochemistry and physiology of bone, Vol I. New York: Academic Press, p 191-121.

Casselman J M. 1974. Analysis of hard tissue of pike, Esoxlucius $\mathrm{L}$. with special referenceto age and growth. In: Bagenal TB, editor. The ageing of fish: proceedings of an international symposium. London: Unwin Brothers Ltd, p 13-27.

Casselman J M. 1978. Calcified tissue and body growth of northern pike, Esox lucius Linnaeus. PhD thesis, University of Toronto, Toronto Ontario. $782 \mathrm{p}$.

Casselman J M. 1983. Age and growth assessment from calcified structures: techniques and tools. In: Proceedings of the international workshop on age determination of oceanic pelagic fishes: tunas, billfishes, and sharks. Miami, February 15-18, 1982. US Dept Commerce, NOAA Tech Rep NMFS 8:1-17.

Casselman J M. 1987. Determination of age and growth. In: Weatherley AH, Gill HS, editors. The biol ogy of fish growth. London: Academic Press, p 209-242.

Chilton DE, Beamish RJ . 1982. Age determination methods for fishes studied by the groundfish program at the Pacific Biological Station. Can Spec Pub Fish Aquat Sci 60:102 p.

Clayden EC. 1952. A discussion on the preparation of bone sections by the paraffin wax method with specieal reference to the control of decalcification. J Med Lab Technol 10:103-123.

Dingerkus G, Uhler LD. 1977. Enzyme clearing of alcian blue stained whole small vertebrates for demonstration of cartilage. Stain Tech 52:229-232.

GauldieRW, Nelson DGA. 1988. Aragonitetwinning and neuroprotein secretion are the cause of daily growth rings in fish otoliths. Comp Biochem Physiol 90:501509.

Geerlink PJ . 1983. Pectoral fin kinematics of Cronsis formosa (Labridae, Teleostei). Neth J Zool 33:515531.

Geerlink PJ . 1989. Pectoral fin morphology: a simple relation to movement pattern? Neth J Zool 39:166193.

Geerlink PJ, Videler JJ. 1987. The relation between structure and bending properties of the teleost fin rays. Neth I Zool 37:59-80.

Geraudie J , Landis WJ . 1982. The fine structure of the developing pelvic fin skeleton in the trout, Salmo gairdneri. Am J Anat 163:141-156.

Geraudie J , Landis WJ . 1989. Mineral deposition in the developing pelvic fin bud of the trout, Salmo gairdneri. Connect Tissue Res 22:224-230.

Grynpas MD, Holmyard D. 1988. Changes in quality of bone mineral on aging and in disease. Scan Microsc 2:1045-1054.

Hikita T. 1962. Ecological and morphological studies of the genus, Oncorhynchus (Salmonidae) with particu- lar consideration on phylogeny. Sci Repts Hokkaido Salmon Hatchery 17:1-99.

Holland ND, Holland LZ. 1991. The histochemistry and fine structure of the nutritional reserves in the fin rays of the lancet, Branchiostoma lanceolatum (Cephal ocordata=Acrania). Acta Zool (Stockholm) 72: 203-207.

Humason GL. 1967. Animal tissue techniques, 2nd ed. San Fransico: W.H. Freeman and Co.

International North Pacific Fisheries Commission 1959 Proceeding of theAnnual Meeting $1958.73 \mathrm{p}$.

Landis WJ , GeraudieJ . 1991. Organization and devel opment of the mineral phase during early ontogenesis of the bony fin rays of the trout, Oncorhynchus mykiss. Anat Rec 228:383-391.

Lanzing WJ R. 1976. The fine structure of fins and finrays of Tilapia mossambica (Peters). Cell Tissue Res 173:349-356

Luft J H. 1961. I mprovements in epoxy resin embedding methods. J Biophys Biochem Cytol 9:409-414.

MacLellan SE. 1987. Guide for sampling structures used in age determination of pacific salmon. Nanaimo, BC: Dept. of Fisheries and Oceans, Fisheries Research Branch. Pacific Biological Station. p 1-27.

Moss ML. 1961a. Studies of the acellular bone of teleost fish. I. Morphological and systematic variations. Acta Anat 46:343-362.

Moss ML. 1961b. Osteogenesis of acellular teleost fish bone. Am J Anat 108: 99-110.

Moss ML. 1963. The biology of acellular teleost bone. Ann NY Acad Sci 109:337-350.

Moss ML, Posner AS. 1960. X-ray diffraction study of acellular teleost bone. Nature 188:1037-1038.

Mugiya Y. 1966. Calcification in fish and shell-fish VI Seasonal change in calcium and magnesium concentrations of the otolith fluid in some fish, with special reference to the zone formation of their otolith. Bul J pn Soc Sci Fish 32:549-557.

Nation J L. 1983. A new method using hexamethyldisilazane for preparation of soft tissue insect tissues for scanning electron microscopy. Stain Technol 58:347351.

Norris WP, Charin W, Lombard LS. 1963. Studies of calcification in the marine teleost. Ann NY Acad Sci 109:312-336.

Padykula HA. 1988. Histochemistry and cytochemistry. In: Weiss L, editor. Cell and tissue biology. a textbook of histology. Baltimore: Urban and Schwartzenberg Inc. p 93-113.

Parenti L. 1986. The phylogenetic significance of bone types in euteleost fishes. Zool J Linn Soc Lond 87:3751.

Potthoff T. 1974. Osteological development and variation in young tuna, genus Thunnus (Pisces, Scombridae) from the Atlantic Ocean. Fish Bull US 72:563-

Potthoff T, Kelley S. 1982. Development of the vertebral column, fins and fin supports, branchiostegal ray and squamation in the swordfish, Xiphias Gladius. Fish Bull 80:161-186.

Prince EC, Pulos LM, editors. 1983. Proceedings of the international workshop on age determination of oceanic pelagic fishes: tunas, billfishes, and sharks. Miami, February 15-18, 1982. US Dept. of Commerce, NOAA Tech Rep NMFS 8. $211 \mathrm{p}$.

Reid SA, Boyde A. 1987. Changes in mineral density distrubution in human bone with age: image analysis using backscattered el ectrons in the scanning el ectron microscope. J Bone Min Res 2:13-22.

Robinson RA, Poly SB, Cooper RR. 1977. Electron microscopy of mammlian bone. In: Zipkin I, editor. Biological 
mineralization. New York: J ohn Wiley and Sons. p 257-298.

Romer AS, Parsons TS. 1986. The vertebrate body. Philadelphia: WB Saunders.

Schour I, Hoffman MM. 1949. Studies in tooth development. J Dent Res 15:91-102.

Sheehan DC, Hrapchak BB. 1980. Theory and practice of histotechnol ogy. St. Louis: CV Mosby.

Skedros J G, Bloebaum RD, Boyce TM. 1991. Relationship of graylevels in backscattered el ectron images of stimulated bone tissue to atomic number, density and mineral content. Sixteenth Annual Meeting of the Society for Biomaterial. May 20-23, Charleson, SC. p 53.
Taubert BD, Coble DW 1977. Daily rings in otoliths of three species of Lepomis and Tilapia mossambica. J Fish Res Board Can 34:332-340.

Warshawsky H, Moore G. 1967. A technique for the fixation and decalcification of rat incisors for electron microscopy. J Histochem Cytochem 15:542-549.

Weiss RE. 1978. The comparative biol ogy of osteogenesis and resorption of fish bone. PhD Dissertation, University of South Carolina, Columbia, SC. $180 \mathrm{p}$.

York B. 1987. A guide to processing fin rays for ageing purposes. Nanaimo, BC: Dept. of Fisheries and Oceans, Fisheries Research Branch. Pacific Biological Station. p 1-17. 